\title{
The Resilience of Early Childhood Parenting Style in the Disruptive Era
}

\author{
Deflita R. N. Lumi*, Febri Kurnia Manoppo, Rolina A.E Kaunang \\ Department of Christian Religious Education \\ Manado State Christian Religion Institute \\ Manado, Indonesia \\ *deflita.stakn@gmail.com, febri_manoppo@yahoo.com,rolina.ae.kaunang@gmail.com
}

\begin{abstract}
Parenting among children and the elderly includes physical needs, among others (eating, drinking, etc.) as well as psychological needs such as (a sense of security, affection, and others). It is intended that the child is able to adapt and live in harmony with the environment. Disruptive era presents challenges for parents in early childhood parenting. Accordingly, this study aims to describe the parenting resilience of Early Childhood in the era disruptive. This study used a qualitative approach with the method of observation, interviews, and documentation. This study took 47 samples of parents of young children (aged 0-6 years) are scattered in several districts and cities in North Sulawesi Province. The results of this study showed that parenting resilience widely applied by parents is permissive style. This research is expected to be useful to provide an alternative approach about the resilience Parenting of Early Childhood in the disruptive era.
\end{abstract}

Keywords: parenting resilience, childhood, disruptive era

\section{INTRODUCTION}

North Sulawesi Province consists of several town like Manado, Bitung, Tomohon and Kotamobagu which did not escape the Digitalization of information flows. This affects many aspects of life that trigger disruptive era. Parents and Teachers has experienced the impact of this disruptive era.

One of the perceived impact of lifestyle changes that occur from generation to give effect to the Early Childhood Parenting. Each generation has a different upbringing. Parenting parents in treating children, educate, guide, and discipline and protecting the child in achieving process maturity, up to the efforts to establish the norms expected by society in general and then shifted and has its own challenges in the era of this disruption. The emergence of high-tech gadget with its sophistication, an exciting online game design, as well as YouTube channel which present a wide range of crosscountry knowledge into products of era of disruption that could affect parenting which has been there all along [1]. Based on this background, the research team wanted to describe what kind of parenting that can survive in this disruptive era?, what are the factors that make parenting survive in this disruptive era?
An understanding of parenthood is very important for the growth of children from generation to generation along with modernization. In this generation, it is generally more use modernization to form a much smaller display. Because he was born in a technological era, where life is better, as well as the physical needs of the relatively quieter, safer and easier. The generation that includes some aspects of the millennial generation only in the era of disruptive.

The development of this generation happens in all parts of Indonesia, from Sabang to Merauke. Since parenting is the thing that determines the future of the next generation, the generation of disruptive era, thus generation in the era of digitalization have to understand it. This is to prepare them in terms of resilience to Early childhood Parenting into the future.

Early childhood age starting from age 2 to 6 years [2]. Character of children at an early age is the tendency of the most difficult to manage. This is because children at this age are in a stage of development that wanted freedom. This is apparent from their stubborn behavior, fighting, disobedient, angry for no reason, as well as irregular sleep time. In the psychology, children ages two to six years begin to experience changes in progress including motor skills, cognitive, language and social skills [3].

\section{METHODS}

This study used a qualitative approach with the method of observation, interviews and documentation study. This study took 47 samples of parents of young children (0-6) years in several Districts and Cities in North Sulawesi Province. This research is expected to be useful to provide an alternative approach about the resilience Parenting of Early Childhood in the disruptive era.

\section{RESUltS AND DISCUSSION}

\section{A. Set Limits, Give an Understanding to the Children, and Responsive to Their Emotional Needs}

In general, every generation populations that appear within each of the last 15-18 years have a different demographic characteristics with the generation before and after. This characteristic grouping known as the cohort generation which 
represents the division of a generation which is based on periodization time as well as differences in the characteristics of the group. Characteristic of each generation is different in terms of trust, confidence, career, balance work, family, gender roles, environment and jobs [4]. For example, the generation born in the years 1946-1964 known as the baby boomers. The generation born in the years 1965-1979, known as Generation $\mathrm{X}$ (Slacker or Xers). Generation Y is a generation born 19802000. This generation is often also referred to as digital or millenials generation, the generation born in the era of disruption. The birth of this generation, namely when the internet began to enter and flourish (NET generation). While different from the generation born after the millennial era is better known as the $\mathrm{Z}$ generation.

Each generation has different characteristics because it is determined by many factors. For example, a factor of change and demographic conditions at the time. Generation $\mathrm{X}$ is not equal to the Net generation that relies heavily on technology especially internet browsing [5]. These children were born on the condition of the world better than the previous generation. The parents in this generation the majority of the more established, better able to provide the facilities and comfort to the child. Kids at this age have a great ambition to succeed and grow because of the increasing number idolized role model than the previous generation. Kids of this generation have the ambition or goal early on. Therefore, parents need to define and child to a goal or ideal of a child clearly and correctly. Early childhood tend to think practically and behave in an instant (speed). This generation of early childhood love towards solving practical problems and lack the patience to follow the process and also to look at a problem. This is because these children were born in a world of almost instantaneous and easy [6]. This reality requires parents to care for children with resilience, durability and commitment to perform duties as parents [7]. Parents are obliged to lead a child to find ways and practical steps in helping her find purpose in life.

Millennial generation in the era of disruptive so fond of freedom in the opinion, imagination, creativity and expression. Kids of this generation born in the world of modernity. A world with characteristics and understanding that tyrannical authoritarian regime has no power to control the other. This generation of children more interested in subjects that are exploratory and do not have any interest in subjects that are memorized. Their minds could are raise so many questions in life. They need logical explanation of every single rule which apply at home or their environment. Therefore, parents need to provide a logical explanation of the regulations applied.

However, the concept of responsible freedom to children, is still very limited. Pattern foster resilience in terms of early childhood should not let children free without understanding the principles of cause and effect. This is also the reason for parents to apply Authoritative Parenting [8] as parenting style in the Age of disruption in Early Childhood as stated by 16 parents with educational background in Tahir, aged 25-40 years Characteristics of patient and wise. Set limits, give an understanding to the children, and responsive to their emotional needs are three principal things in their parenting style. Parents who apply authoritative parenting style are usually very warm to their children, and emphasize the reasons the enactment of rules. This condition makes children be able to grow into a more independent, socially acceptable, success in academic, and well behaved.

\section{B. Tends to be Responsive to Their Children, but Free of the Rules and Discipline}

The second style of parenting is permissive parenting or indulgent parenting. Parents with a permissive parenting tend to be responsive to their children, but free of the rules and discipline [9]. Parents with this style of parenting rarely stated the demands and expectations of the child. Parents understand that they have to create a conducive environment so that children grow in competence and have high confidence, without intimidation or the rules and strict discipline. Children who grew up with this style tend to grow up without discipline. Children are allowed to grow and shaped by things around. The child can be a friend and is considered to form a behavior based on the things they see or child is believed to be able to choose for themselves what is best for him. There were 25 parents with educational background in high school, ages 20-30 years, with different characteristics of early childhood implement this as parenting style for young children.

\section{Providing Strict Rules, Harsh Punishment, Just Give a Little Insight to the Child, and Less Friendly to Children}

The third parenting style is an Authoritarian Parenting. In this parenting style, parents often said, "When the mother / father of your age, mother / father was able to ..." . Parents also give strict rules, harsh punishment, just give a little insight to the child, and less friendly to the children. This parenting style prefers threaten the child with the hope and the child is afraid to make mistakes and be obedient. Resilience is considered a hard rule for their child parenting style. Authoritarian Parenting is a parenting style which considers that the child just need to understand that the elderly owner of the supreme decision of his life without the need to give children the opportunity to understand the things that should be part of his life to shape the future of good character [10]. Early Childhood Parents do these things and consider Parenting is a pattern matching and can be maintained in this disruptive era.

\section{CONCLUSION}

Parents' personality differ in the level of patience, intelligence, attitude and maturity. Thus, parents' belief about parenting will affect the value of parenting and will influence their behavior in taking care of their children. When parents feel that their parents were successfully implemented parenting their children, a similar technique would be used in terms of their children's upbringing. But if the parents thought that they were treated inappropriately by their parents, they will turn into other parenting techniques. In addition, there are some factors which influence young parents in considering and applying the appropriate parenting to address challenges in this disruptive era. The results of this study showed that parenting resilience widely applied by parents is to form permissive, followed by an authoritative shape, and the least is the authoritarian form. The 
[3] U. Hasanah, M. Deiniatur, "Character Education in Early Childhood Based on Family", Early Child. Res. J., ISSN: 2655-9315 Print ISSN: 2655-6448.

research team recommends authoritative parenting as parenting styke which was considered quite appropriate to address challenges in this disruptive era. Authoritative parenting style tends to delegate a controlled freedom for their children. This approach is considered to respond to developments in the information technology era this disruptive but not abandon the principles of proper upbringing and should be done by parents. Therefore, this study would be useful to provide insight as well as alternative approaches on Early Childhood Parenting which are able to demonstrate resilience in this disruptive era [11].

\section{ACKNOWLEDGMENT}

The author thanks Dr. Jeane Marie Tulung as IAKN Rector in Manado who has supported writers to be motivated and write. Also, for all speakers and for the research team who give contribution to this paper.

\section{REFERENCES}

[1] I. Martínez, S. Murgui, O.F. Garcia, F. Garcia. "Parenting in the digital era: Protective and risk of parenting styles for traditional bullying and cyberbullying victimization", Comput Human Behav, vol. 90, pp. 84-92, 2019.

[2] Z.J. Ward, "2-6 years-of-age is the period associated with BMI greatest acceleration among obese adolescents", J. Pediatr., vol. 206, pp. 299300, 2019.

[4] R. Ladhari, J. Gonthier, M. Lajante, "Generation Y and online fashion shopping: Orientations and profiles”, J. Retail. Consum. Serv., vol. 48, pp. 113-121, 2019.

[5] V. Roblek, M. Mesko, V. Dimovski, J. Peterlin, "Smart technologies as social innovation and complex social issues of the $\mathrm{Z}$ generation", Kybernetes, vol. 48, no. 1, pp. 91-107, 2019.

[6] S. Awasthi, T. Verma, T. Sanghvi, E. A.Frongillo, "Path to severe acute malnutrition in children below 2 years of age: Findings of a qualitative research in Uttar Pradesh, North India", Clin. Epidemiol. Glob. Health, vol. 7, no. 2, pp. 246-252, 2019.

[7] L.M.N. Fernando, W. H. Sim, A. F. Jorm, R. Rapee, K. A. Lawrence, M. B. H. Yap, "Parenting Resilient Kids (PaRK), an Online Parenting Program to Prevent Anxiety and Depression Problems in Primary School-Aged Children: Study Protocol for a Randomized Controlled Trial", vol. 19, no. 1, 2018.

[8] A. Turvill, D. Fido, E. Parker, "Early childhood technoference threat is predicted by authoritative parenting, but not parental knowledge of digital risks", DOI: 10.31234/osf.io/9t4dp, 2019.

[9] M. Cui, J. A. Graber, A. Metz, C. A. Darling, "Parental indulgence, selfregulation, and young adults' behavioral and emotional problems", J. Fam. Stud., vol. 25, no.3, pp 233-249, 2016.

[10] Y.J. Seo, “The Mediating Role of Korean Immigrant Mothers' Psychological Well-Being in the Associations between Social Support and Authoritarian Parenting Style", J. Child Fam. Stud. vol. 27, no. 3, pp. 979-989, 2018.

[11] E.B. Hurlock, Child Development Volume II, translation Tjandrasa, Erland: Jakarta, 1999 